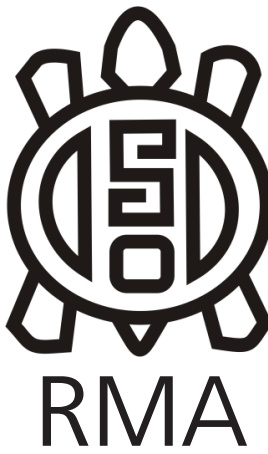

Dossier

Wichí: La gente

\title{
A la sombra de los tobas. Los noctenes (weenhayek) de San Antonio del Pilcomayo, siglo XIX
}

\author{
In the shade of the Tobas. The Noctenes (Weenhayek) of San Antonio \\ del Pilcomayo, 19th century \\ Isabelle Combès*
}

*Instituto Francés de Estudios Andinos (UMIFRE 17 MAEDI/CNRS USR 3337 América Latina) / Centro de Investigaciones Históricas y Antropológicas ( $\mathrm{ClHA})$, Santa Cruz de la Sierra, Bolivia. E-mail: kunhati@gmail.com

\begin{abstract}
Resumen
A partir principalmente de fuentes franciscanas inéditas, se reconstruye la historia de la misión de San Antonio entre los "noctenes" (actuales weenhayek) del Pilcomayo en el Chaco boliviano, durante la segunda mitad del siglo XIX. Sobresalen los estrechos lazos con los tobas y la recurrente "apatía" de los noctenes, que se interpreta a partir de los estudios de John Palmer sobre "la buena voluntad wichi".
\end{abstract}

Palabras clave: Noctenes; Weenhayek; Chaco boliviano; Misiones franciscanas; Resistencia.

\begin{abstract}
Based mainly on unpublished Franciscan sources, the paper reconstructs the history of the San Antonio mission among the "Noctenes" (present-day Weenhayek or Wichi) of the Pilcomayo in the Bolivian Chaco during the second half of the 19th century. The close ties of these Noctenes with the Toba and their recurrent "apathy" stand out in the regional literature, which is interpreted from the point of view of John Palmer's studies on "Wichi goodwill".
\end{abstract}

Keywords: Noctenes; Weenhayek; Bolivian Chaco; Franciscan Missions; Resistance.

Esta sentencia y significativa frase chiriguana [...] se puede poner por texto a la historia de los noctenes y tobas, para uno que entiende la lengua, costumbres y modo de obrar de todo indio, pero de un modo especial de tobas y noctenes [...], y es a saber:

Toba, toba có, cha toba no? Hottenai, hottenai có, cha tobañoñe no?

(Giannecchini, 1879a, f. 3)

La caridad cristiana no siempre inspira a los misioneros más abnegados. En el Chaco boliviano del siglo XIX, los padres franciscanos de Tarija evangelizan a indígenas chiriguanos (de habla guaraní), tobas (de la familia lingüística guaycurú) y noctenes (de la familia lingüística mataco-mataguaya). Al decir de los padres, estos últimos son viles y ociosos, indiferentes y apáticos; son fríos y hasta glaciales, inconstantes y postrados, flojos, sucios, cobardes y traicioneros. Por cierto, juicios de esta naturaleza tampoco escasean para calificar a chiriguanos ruines y malvados o a los pérfidos tobas, pero no se emiten tan sistemáticamente, ni con la misma magnitud. Para franciscanos italianos, criollos bolivianos y no pocos indígenas vecinos, los noctenes parecen concentrar todos los defectos imaginables, a la vez que ser inconsistentes, amorfos, presas de una inconcebible apatía. Más aún, los noctenes ni siquiera parecen tener historia propia. En las fuentes escritas, la suya es una historia rezagada, que repite en un registro más apagado la vivencia de sus vecinos tobas. Entraron por primera vez en una misión franciscana en 1860, pero esta misión fue fundada para los tobas; huyeron de la misma varias veces, "influidos" por los tobas; robaron y asesinaron, empujados por los tobas, actuando como sus cómplices, sus espías o sus criados. ¿Toba, toba có, cha toba no? Hottenai, hottenai có, cha tobañoñe no? ['Los tobas, ¿tobas son, tobas pues, no? Los noctenes, ¿noctenes son, tobas no más, no?'], decían los chiriguanos; "alcahuetes de los tobas", ponderaban los franciscanos. Acercarnos a esta historia inexistente, ninguneada por las fuentes y subordinada a la de otros, es el objetivo de estas páginas.

\section{Surgen los noctenes}

Los antiguos noctenes se llaman hoy weenhayek o weenhayek wichi ('la gente diferente') y, al igual que en el siglo XIX, están asentados en la orilla derecha del río Pilcomayo, en la provincia Gran Chaco del departamento boliviano de Tarija. Forman parte del conjunto étnico 
wichí, más numeroso en la vecina República Argentina'.

Poco es lo que conocemos de su historia, y prácticamente nada si se trata de épocas remotas. Si bien la bibliografía antropológica sobre los wichís es inacabable, la de corte histórico es mucho más reducida. Más aún, la literatura versa en su inmensa mayoría sobre la Argentina donde vive la mayor parte de los wichís. Aunque las investigaciones sobre aquellos que viven del lado boliviano se hayan multiplicado en los últimos años, siguen siendo más escasas. Precursores fueron Rafael Karsten y, luego, Edgar Ortiz Lema en 1986, seguidos por Jan-Åke Alvarsson; más tarde otros estudios provienen del Centro de Estudios Regionales para el Desarrollo de Tarija (CERDET), y surgen también investigaciones de corte lingüístico².

Si bien todos estos estudios incluyen un inevitable apartado histórico, conozco a un solo libro enteramente dedicado a la historia de los weenhayek, el de Alvarsson (2012). Tanto este libro como los capítulos más o menos generales de las demás publicaciones se basan, por una parte, sobre fuentes orales, y por otra en documentación histórica secundaria. Más aún, la historia así reconstruida abarca en general al conjunto wichí, con noticias del Chaco argentino más que todo, y sólo a partir de mediados del siglo XIX llega a convertirse en historia propiamente weenhayek. Es un hecho que la memoria oral no se remonta mucho más allá del siglo XIX (o, cuando lo hace, cae en general en el relato mítico más que propiamente histórico) y, en el caso weenhayek, las fuentes escritas tampoco se remontan mucho más allá. Sólo empiezan a aportar información válida a partir de 1843, cuando inician las exploraciones criollas al Pilcomayo, y se multiplican en años posteriores con la presencia franciscana en la región. Con todo, como vamos a constatar, estas fuentes son bastante más numerosas que las solas crónicas publicadas que son las que hasta ahora han utilizado los investigadores que más se interesaron por la historia de los "noctenes".

En la época colonial los wichís del Gran Chaco son conocidos en las fuentes históricas como mataguayos y matacos, términos genéricos y despectivos de probable origen quechua. A finales del siglo XVIII, conforme al tímido avance de la colonización, nuevos nombres empiezan a aparecer, como subdivisiones del conjunto mataco: abuchetas, vejoces, etc., algunos de ellos identificables como nombres de parentelas wichís ${ }^{3}$. Pero no siempre ni en todas partes. En el alto Pilcomayo,

\footnotetext{
1 Se estima el número de wichí-hablantes en aprox. 4.000 en Bolivia (Nercesian, 2013). Según la grafía adoptada, el etnónimo puede escribirse 'weenhayek o w'enhayek, pero en los textos más difundidos y la propia constitución política de Bolivia, se escribe simplemente weenhayek. Adopto aquí esta grafía por ser más sencilla y más común, aunque no necesariamente más correcta.

2 Karsten, 1913; Ortiz Lema, 1986; Alvarsson, 1988, 2012; Cortez, 2006; Claesson, 2008; Nercesian, 2013, entre otros.

3 Acerca de la etnonimia wichí/weenhayek, remito a Montani y Combès 2018
}

donde viven hoy los weenhayek, reina la más completa incertidumbre. Frontera oriental de la Audiencia de Charcas y frenando el avance colonizador hacia el Este, el piedemonte andino, conocido en la Colonia como la "Cordillera chiriguana", se erigió durante siglos en un formidable escudo de protección para el Chaco. La fiera resistencia chiriguana al español resguardó a los pueblos chaqueños hasta mediados del siglo XIX cuando se dio inicio a una colonización ya imparable. De esta manera las fuentes más antiguas aluden a lo sumo a "tobas" y "matacos", sin mayores precisiones ni detalles. Sólo consta que existen a lo largo del río. Los chorotes y tapietes ni siquiera son mencionados. $Y$ no es pues casualidad que todos estos etnónimos surjan todos juntos y de golpe en la misma fecha, y en el mismo informe del primer explorador del Pilcomayo por el lado boliviano.

En 1843 el presidente de Bolivia es José Ballivián, que pasó a la historia como el que abrió el país a las tierras bajas orientales, hasta entonces poco conocidas y menos aún exploradas ${ }^{4}$. En busca de una salida al océano Atlántico, Ballivián impulsa exploraciones del Chaco boliviano, queriendo encontrar ahí un camino al Paraguay. En la misma época, firma decretos destinados a alentar la colonización de la "frontera" en los llanos chaqueños 5 .

De esta manera, a finales de 1843, una primera expedición fluvial se organiza para reconocer el curso chaqueño del Pilcomayo, al mando del prefecto de Tarija, Manuel Rodríguez Magariños. Los accidentados pormenores de la fracasada exploración poco importan aquí, como tampoco los de la segunda expedición que se desarrolló en 1844 al mando del belga Enrique van Nivel ${ }^{6}$. Lo significativo es que en los informes relativos a ambas tentativas aparecen, por primera vez, informaciones sobre los indígenas del Pilcomayo. Magariños es el primero en mencionar a "tobas, ojtenes, güisnais, matacos y tapietes"7. Nota que los matacos ocupan la ribera derecha del río, que están relacionados con los "ojtenes" y aparentemente también con los "guisnais" de río abajo ${ }^{8}$. A su vez Van Nivel enumera poco después a "tobas, matacos, notenis, chorotés, guisneis, tapietés"9; Girey, jefe "mataco" del alto Pilcomayo, también está relacionado con los "guisneis" o "guisnayes", entre quienes tiene un cuñado ${ }^{10}$. Finalmente, dos años más tarde, el viajero francés Hugues Weddell encuentra a "matacos o jotenes"11.

\footnotetext{
${ }^{4}$ Cf. Groff Greever, 1987; García Jordán, 2001.

${ }^{5}$ Weddell, 1851/2018, p. 174.

6 Magariños, 1844; Van Nivel, 1845; Groff Grever, 1987; Combès, 2019c.

${ }^{7}$ Magariños, 1844 30.04.1844, p. 2. El resaltado es mío.

${ }^{8}$ Magariños habla de un encuentro "con más de 400 indios matacos y ojtenes", e indica que un mataco de Itiyuru habló de él "a todos los capitanes matacos y ojtenes y al capitán grande de los guisnais" (1844 4.05.1844, p. 2)

${ }^{9}$ Van Nivel, 1844: 3. El resaltado es mío

${ }^{10}$ Van Nivel, 1845 15.03.1845, p. 4

${ }^{11}$ Weddell, $1851 / 2018$, p. 224 . El resaltado es mío.
} 
Magariños, Van Nivel y Weddell utilizaron todos el mismo guía criollo, Celestino Baldivieso, conocedor del idioma guaraní de los chiriguanos. Celestino fue el que presentó a los "matacos o jotenes" a Weddell, y los padres franciscanos confirman más tarde este hecho: "octénai" o "hottenai", transformado luego en "notenes" o "noctenes", es el "nombre que les dan los chiriguanos"12, y que adoptan misioneros y criollos (aunque estos últimos siguen utilizando también el despectivo "matacos"). A lo largo del siglo XIX y en todo el tiempo de existencia de la misión de San Antonio, los franciscanos hablan así de "noctenes", aunque conocieron muy temprano el "verdadero" nombre de sus neófitos: ya en 1864 el P. José Gianelli anotaba que los "notenes" se llamaban a sí mismos guennayei, es decir weenhayek (Gianelli, 1864); Corrado y Ducci anotan respectivamente huennéyei y güenneyéi ${ }^{13}$. Mientras tanto, la primera grafía de este nombre, que surgió también en 1843 como "guisnais" o "güisnayes", desaparece de las fuentes hasta volver a ser mencionada en los años $1880^{14}$, pero como nombre exclusivo de aquellos wichís que viven Pilcomayo abajo, en la zona de Piquirenda.

Aunque "noctenes" no sea un nombre propio, su aparición en las fuentes históricas es significativa: la nebulosa mataca ya no es tal, los colonizadores empiezan a identificar e individualizar algunos grupos, a conocer mejor al Pilcomayo y su gente.

\section{La misión estancada}

Ya sea en su memoria oral (Alvarsson, 2012), ya sea en las fuentes escritas, la historia decimonónica de los noctenes es en gran parte la de sus relaciones con tres diferentes actores: el frente de colonización, encarnado por los padres franciscanos italianos y los colonos criollos; los tobas; y los chiriguanos. Los otros grupos étnicos de la comarca como los chorotes o los tapietes prácticamente no aparecen.

Los noctenes no tienen buenas relaciones con ninguno de sus vecinos. Los colonos quieren explotar su mano de obra y usurpar sus territorios; los franciscanos son buscados como protección contra los criollos, pero pretenden imponer nuevas normas y una nueva religión. Los chiriguanos son llamados suwele, que es el nombre también aplicado a los criollos, pues a ojos wichís no se diferencian mucho de ellos. No solamente su modo de vida (sedentarismo, agricultura) es diferente del de los noctenes, sino que pretenden en ocasiones adueñarse de su territorio (cf. Alvarsson, 2012, pp. 39-40) y tratan a todos los indígenas chaqueños con un soberbio desprecio

\footnotetext{
${ }^{12}$ Corrado, 1884, p. 535; Ducci, 1895, p. 27; Giannecchini, 1898/1996, p. 121. Lo más verosímil es que el término provenga del nombre dado por los chorotes a los wichís del alto Pilcomayo (Montani y Combès, 2018).

13 Corrado, 1884, p. 535; Ducci, 1895, p. 27.

14 Giannecchini, 1883/2006b, p. 625; Campos, 1888, pp. 112-113, 120, 123.
}

(Bossert, 2012; Combès, 2015). Más afinidad existe entre noctenes y tobas, ambos "chaqueños típicos", que comparten no pocos rasgos culturales. Existen además testimonios de matrimonios interétnicos entre tobas y noctenes (calificados en una ocasión como "semi-tobas" [Dimeco, 1878, f. 6]), y actúan a menudo juntos en caso de robos o asaltos a los criollos. Sin embargo estas alianzas estratégicas no impiden que las relaciones entre ambos grupos sean por lo general pésimas y desconfiadas. Nota John Palmer que, ahí donde los wichís convivieron con los tobas, "siempre se han producido dificultades", y Alvarsson por su parte recogió varios relatos de guerra entre los antiguos weenhayek y los tobas bolivianos (Palmer, 2005, p. 159; Alvarsson, 2012, pp. 52-53).

Ya desde el primer informe de Magariños aparecen las alianzas guerreras entre matacos y tobas y, al mismo tiempo, las tensas relaciones entre ellos. En varias ocasiones el explorador es amenazado por grupos nutridos de guerreros matacos y tobas, y en una por "guisnais, tobas y matacos" juntos"15. Más tarde Van Nivel sostiene que "tobas y otenis" acechan juntos río abajo para asaltar su flotilla (1845 8.03.1845, p. 3). Sin embargo, al mismo tiempo, los tobas no se hacen problemas para acusar a los matacos de todos los males ("me mandaron decir que los tobas eran mis amigos [...] y que los matacos eran los malos"16), y tampoco los matacos en devolverles la cortesía: el toba Yumay engaña a los exploradores, según Van Nivel, y el mataco Girey "lo condena"; más aún se presta "gustoso" a ayudar a los viajeros, agregando que "Yumay era un pícaro que no conocía el Paraguay, y que él nos llevaría"17.

A las primeras noticias detalladas de la década de 1840 sobre los indígenas del Pilcomayo sucede un nuevo silencio de casi quince años. Los criollos no se aventuran más Pilcomayo abajo, pero sí están establecidos en Caiza, la ciudad-fortín fundada por Magariños en las puertas del Chaco. Los misioneros se acercan también, con la fundación de Aguairenda en 1851 y la de Tarairí en 1854, entre chiriguanos. Los tobas (y, probablemente, varios noctenes) roban regularmente reses y caballos de los puestos ganaderos, desatando la furia de los colonos y expediciones vengativas que acaban acosando a los indígenas. Es entonces cuando, desde Tarairí, el P. Alejandro Corrado entra en tratativas con un grupo de tobas que no sólo suscribirán un tratado de paz en 1859, sino que formarán el primer núcleo de la misión de San Francisco Solano a orillas del Pilcomayo, que se formaliza en $1860^{18}$.

Si bien el tratado de paz sólo menciona a "tobas", el hecho es que en 1860 son más de 600 tobas y noctenes los que

\footnotetext{
15 Magariños, 1844 27.04.1844, pp. 2-3; 1844 30.04.1844, p. 3.

16 Magariños, 1844 2.05.1844, p. 2.

${ }^{17}$ Van Nivel, 1845 13.03.1845, p. 3; 1845 15.03.1845, p. 4. Itálicas de origen.

${ }^{18}$ Corrado, 1884, p. 402 y sig. Ver Combès, 2019b, cap. 2.
} 
realmente esperan entrar a la nueva misión (Gianelli, 1860; énfasis mío). Un año después, "un número muy crecido de notenes ya se han replegado a San Francisco Solano" (Gianelli, 1861). La nueva misión de los tobas arranca, pues, con un significativo porcentaje de noctenes entre sus pobladores (Giannecchini, 1898/1996, p. 181).

La esperanza despertada entre los franciscanos por esta primera misión chaqueña dura muy poco. Malas cosechas y hambruna dispersan pronto a los indígenas, que salen al monte o a los pueblos criollos vecinos en busca de alimento: en 1862, "en San Francisco apenas quedaban unas 100 personas, comprendidas las mujeres y niños; y aun éstas no paraban fijamente" (Corrado, 1884: 412). Probablemente influyó, también, cierto hastío por la vida misional a la cual los tobas (y los noctenes) nunca se acostumbraron.

En todo caso, la situación es aprovechada por los chiriguanos todavía rebeldes de Guacaya, Cuevo y Macharetí, por los tobas que no estuvieron en las misiones y por otros grupos como los tapietes para asaltar varias misiones, y primero la de San Francisco en octubre de 1862 (Corrado, 1884, p. 414). Aunque violentos, los asaltos son finalmente rechazados. Sus protagonistas son los indígenas que rechazaban la misión franciscana más que los propios neófitos, aunque algunos sí se pliegan al movimiento. En todo caso, la agitación tiene dos consecuencias importantes: primero, los franciscanos toman precauciones e instalan en San Francisco a 50 familias chiriguanas de Tarairí, más confiables que los inconstantes tobas; segundo, los tobas de San Francisco, "temerosos de que pudiera recaer sobre ellos el castigo de la alevosía de sus compatricios, en lugar de volver a la misión, refugiáronse a sus antiguas guaridas" (Corrado, 1884, p. 418). A fin de año sólo viven los chiriguanos advenedizos en San Francisco. De los noctenes no se dice nada, y no sabemos si permanecieron en la reducción o huyeron junto con los tobas.

Llega 1863, y Gianelli decide unirse a una nueva expedición al Pilcomayo dirigida por el militar Andrés Rivas. Las autoridades quieren construir el fuerte de Bella Esperanza en Taringüiti, Pilcomayo abajo, y ven también conveniente la fundación de una nueva misión en este lugar. En cuanto a Gianelli, pretende, primero, reconvenir a los tobas de San Francisco y repatriarlos a su misión; segundo, edificar la nueva misión en Bella Esperanza, con "la primera nación que conquistase" (Gianelli, 1863, f. 2).

En el inicio de su periplo, Gianelli encuentra a varios matacos, que le dicen: "no queremos vivir más en sociedad de estos asesinos tobas" (como lo hacían en San Francisco); en este momento Gianelli decide que la nueva misión será "de matacos" (Gianelli, 1863, f. 8). San Antonio de Padua nace así en agosto de 1863, al amparo del fortín de Bella Esperanza (Gianelli, 1863, f. 14; Documentos..., 1863). Pero -y pese a los explícitos deseos de los noctenes- hasta esta misión "propia" está prevista, en un inicio, para acoger tanto a noctenes como a tobas: "pronto reunirá muchos tobas y matacos", afirma Gianelli (en Documentos, 1863).

Con el propio Gianelli como primer conversor, San Antonio empieza su accidentada trayectoria como misión. Los inicios en Bella Esperanza no son alentadores. Para empezar, los tobas que debían integrar la misión viven en realidad fuera de ella, y hostigan tanto al fraile como a sus neófitos matacos (Gianelli, 1863, ff. 15-16). Más aún, estos tobas están en buenos términos con los soldados del fortín que proyectan sublevarse. Otra traba es el terreno de la misión, que no hace honor al nombre del fortín: es seco, estéril, lleno de sabandijas, hormigas que destruyen todo a su paso y tigres que acechan. Tres años de siembra no permiten ni una sola cosecha, y Gianelli se ve obligado a almacenar chañar para dar de comer a sus catecúmenos e impedir su desbande. Por último, los noctenes desesperan a su conversor. Le ocultan los enfermos para que no los bautice, continúan con sus entierros paganos, se niegan a cultivar y abrir chacras pues "por abusión creían se enojase el monte si cortaban árboles" (Gianelli, 1863, f. 15); van y vienen, y nunca permanecen por muchos días en la misión.

Este estado de cosas, unido a los rumores de un próximo motín de los soldados (que de hecho ocurre poco después), provocan la retirada de Gianelli y su gente río arriba:

Después de dos años y medio de trabajosas porfías, habiéndose reconocido que el terreno de Bella Esperanza es demasiado estéril para sostener una misión ya por su calidad salitrosa, ya por la escasez de lluvia; condescendiendo con los deseos e instancias de los misioneros noctenes, el día 23 de mayo de este año de 1866, el R. P. conversor Fr. José Gianeli [sic], acompañado de las familias de los mencionados indios, se vio precisado a abandonar ese lugar y todos los adelantos hechos en él, con el objeto de trasladar la misión a un punto más ventajoso, que produjese víveres necesarios a la conquista y sustento de estos naturales. Para el efecto se escogió un punto a distancia de como 10 leguas al poniente del citado fuerte de Bella Esperanza, río arriba, al pie de la Peña Colorada; y el día 18 [de] julio del referido año, con las correspondientes facultades, se comenzó el trabajo del nuevo pueblo ${ }^{19}$.

Comienza así la segunda etapa de la misión de San Antonio, ya establecida en la Peña Colorada frente a la misión toba de San Francisco Solano. En 1869, 600 noctenes viven en la reducción (Corrado, 1884, p. 430),

\footnotetext{
${ }^{19}$ Nota del libro de bautismos, firmada por el P. Corrado, en Marcelleti, 1878a, f. 1
} 
con los mismos problemas crónicos que ya se advirtieron en Bella Esperanza. Entran y salen de la misión a su antojo y Corrado comenta, años después:

La cosecha sólo unas semanas podía bastar a su voracidad. Lo demás del año, la pasaban o con la pesca, o con frutas selváticas. Por ello desamparan frecuentemente la misión e íbanse a vivir por largas temporadas en los montes y campos, donde sin trabajo encontraban suficiente forraje. Estas ausencias hacía [sic] dificultosísima y casi imposible su civilización (Corrado, 1884, p. 430).

La actitud de los noctenes desalienta a sus sucesivos misioneros, José Gianelli hasta 1870 y, luego, Vicente Marcelleti. Por más que Corrado quiera persuadirse de que muy poco a poco van perdiendo "su selvatiquez", siguen sin aceptar el bautismo y las normas de la misión. En 1867, se les da plazo para que cambien de actitud: pero "el plazo pasó, quedando las cosas como antes" (Giannecchini, 1874, f. 2). Acerca de esta triste época, el padre Giannecchini comenta:

La misión de San Antonio no tiene ni ha tenido nunca vida en sí misma. Es un árbol cuya savia no sale de sus raíces, como la experiencia de tantos años lo ha demostrado, sin que a pesar de las grandes consideraciones que a preferencia de cualquiera otra misión se han usado a sus individuos, los haya podido empeñar a defender por sí mismos a su P. conversor, a su pueblo, a sus familias (1874, f. 1v).

En 1871, el prefecto de misiones consulta a los conversores acerca de "la situación estancada de la reducción de San Antonio entre los matacos", y pregunta si vale la pena continuar un trabajo que a todas luces no está dando frutos (Ercole, 1871).

\section{Se van los tobas y llegan los chiriguanos}

La penosa historia de la misión de San Antonio se complica poco después, a iniciativa de los tobas de la vecina San Francisco. En 1873, al mando de un tal Cuserai, los tobas abandonan su misión y van río abajo ${ }^{20}$. En San Francisco sólo quedan las 50 familias chiriguanas traídas de Tarairí, a las cuales los franciscanos pronto agregan otras ${ }^{21}$.

El problema tiene consecuencias entre los noctenes. Con la primera fuga de los tobas en septiembre, "los débiles y apocados noctenes han dejado sentir su natural inconstancia, retirándose paulatina e insensiblemente de su propia reducción" (Ercole, 1874b). Ya en noviembre, la deserción de los tobas

\footnotetext{
20 Corrado, 1884, p. 471, 473; Anales 1883/2006, p. 1250; Giannecchini, 1885, f. 4; Ercole, 1874b.

${ }^{21}$ Ercole, 1874a; Corrado, 1884, p. 475. Ver Combès, 2019b, cap. 3.
}

...ha influido con eficacia en que los noctenes susodichos entraran en serias desconfianzas y perplejidades. Así es que, lejos de haberse regresado los ausentes de septiembre, de día en día se ha ido aumentando el número de los desertores hasta quedar en la misión apenas una muy reducida fracción, la misma que ya no se conducía ya con la obediencia y sumisión debida a su verdadero amigo y benefactor, queremos decir, al Padre de sus almas (Ercole, 1874b, f. 1).

Hasta que, en la noche del 23 al 24 de enero de 1874, "toditos [los noctenes] se fugaron, quien, de un lado, quien de otro" (Giannecchini, 1879a, f. 5; Ercole, 1874b, ff. 1v, 2v). Tres semanas más tarde, los frailes deciden ir en busca de sus catecúmenos perdidos (Ercole, 1874b, ff. 1v2). Giannecchini relata más tarde el final de esta "fuga":

Respecto a los noctenes, no militando las mismas razones de los tobas, por ser la primera vez que se fugaban, más tal vez por su natural timidez que por alevosía, ni constar claramente la complicidad de ellos con los tobas, la falta que hacía en ese punto la misión, etc., por todas estas razones se determinó hacerlos buscar, reunir y perdonar todos sus yerros. Mas aun antes de todo eso, al empezar mandar trasladar los trastes a S. Francisco y hacer pacer el ganado a la banda con los taraireños que habíamos llamado para el efecto, los noctenes, con la misma frescura con que se habían ido, así empezaron a los pocos días a regresar, para ver qué viento tiraba. $Y$ viendo que se trataba de hacer trasladar vacas, cosas y padres, empezaron con sus acostumbrados mensajes y mentiras, diciendo hacer sido engañado por los tobas, que estaban arrepentidos, que no se amañaban ya por los campos, que los hijos echaban [de] menos al Padre, a la misión, al maíz, a la maestra, que los capitanes los mandaban de embajadores a implorar la admisión de nuevo, que no se volverían a escapar ni seducir de los tobas, avas, y otras cosas por el estilo acostumbrado por ellos -cha toba no?, y sin aguardar respuesta definitiva se empezaron a regresar ${ }^{22}$.

Mientras tanto, en 1874 estalla la mayor rebelión chiriguana del siglo, con Guacaya y Cuevo como epicentros: "la chispa que la deserción de los tobas había arrojado entre las tribus vecinas iba dilatándose, y amenazaba poner en conflagración no sólo nuestras misiones sino todos los pueblos y estancias de las provincias del Azero y del Chaco" (Corrado, 1884, p. 481). Los tobas y, tal vez, los noctenes, participan del conflicto al lado de los chiriguanos, particularmente en los asaltos a varias misiones franciscanas. Entre ellas, la de San Antonio

\footnotetext{
22 Giannecchini, 1879a, f. 6. Ava es la autodenominación de los chiriguanos.
} 
es sin duda la más amenazada y asaltada varias veces: "a no dudarlo es la más abandonada a sí misma. Sus armas son pocas e inseguras; sus indios son de perseverancia y fidelidad problemática" (Ercole, 1874c, f. 1). De hecho, los franciscanos no dudan en acusar a los apáticos noctenes de complicidad encubierta (o no tanto) con los tobas. En uno de los ataques contra la misión,

Tobas y noctenes estaban convoyados para un alzamiento, traición y muerte del padre, conchabados y avas. Ninguno de los noctenes manifestó nada, antes bien tenían al padre engañado con sus acostumbrados imiani ['cuentos'] mentirosos [...] Estaban al corriente de todos los robos que los tobas cometían et manducabant cum illis dándoles parte de todos los movimientos de S. Francisco, S. Antonio y carais ['blancos'] (Giannecchini, 1879a, f. 7, 3-4 respectivamente).

Los misioneros noctenes bien lo supieron antes (los tobas son parientes de varios de éstos) y se dieron casi por desentendidos. Es cierto que, llegados los tobas al pie del pueblo, los noctenes, siquiera a lo externo, les hicieron frente y al retirarse aquellos, éstos los persiguieron. Pero es también cierto que el manejo de los noctenes en aquella circunstancia no fue satisfactorio (Marcelleti, 1878i, ff. 1v-2).

Giannecchini insiste más tarde:

Puedo asegurar sin temor de engañarme que los enemigos tobas y chiriguanos jamás se hubieran atrevido últimamente a invadir, dejando a las espaldas a ésta, si no hubiesen contado con la cooperación o apatía de los mismos misioneros noctenes [...] ellos a boca de noche ya sabían que el enemigo había venido, hablaron con él, él entró a sus ranchos para convenir en el modo de asaltar definitiva y totalmente la misión, y prohibían a sus hijos el hacer palabra de ello al Padre. Esa misma noche el capitán Catuna hizo el necio de lo que pasaba y, preguntado por el Padre, dijo haber oído que los tobas estaban por Iguopeiti, mientras que ya estaban en Capiîrenda y ya habían robado los animales, entrado al pueblo, hablado y regresado al campo del enemigo. El capitán Rubio fue quien más tuvo parte en el parlamento con el enemigo, quien persuadía a los soldados y familias a escaparse y no abrigarse al fuerte. En la pelea que hubo lugar en el puesto al amanecer de aquella misma noche, ellos no pelearon con aquel valor y arrojo que debían hacerlo, dando así lugar al enemigo de poder saquear a gusto: prueba de ello fue el no haber quedado ni uno de ellos herido o muerto, ni ellos a su vez no haber herido ni muerto a ninguno de los enemigos durante el combate y saqueo referido. Ellos han conservado y conservan tanto en tiempo de paz que de guerra comunicaciones continuas con el enemigo. Más, sirven de espías para relatarles los movimientos de ésta, por cuyo motivo todas nuestras expediciones quedan sin efecto. Ellos esparcen noticias de invasiones, de enemigos, de robos, siendo falso, para poner el alarma en ésta; y cuando es realidad callan y ocultan. Son todos hechos consumados y no necesitan de prueba (Giannecchini, 1874, ff. 2-2v).

El resultado es que San Antonio está más expuesta que nunca a los ataques indígenas. Los padres recelan de la fidelidad de sus catecúmenos en caso de "invasión tóbica", y temen una traición (Marcelleti, 1878i, f. 1). La principal debilidad de la misión es su ubicación, en la orilla derecha del Pilcomayo: en época de lluvias, el río crecido no permite que las reducciones de San Francisco, Tarairí o Macharetí puedan socorrerla. Se planea enviar al conversor a San Francisco en tiempo de aguas "y casi diría abandonar y dejar del todo y para siempre a los noctenes, atendida su mala fe con que siempre [...] han procedido" (Giannecchini, 1874, f. 2v). Sin embargo, otros poderosos motivos influyen para no desamparar la misión: se trata pues de un punto estratégico en la carretera que une Bolivia con la Argentina, y de hecho son los catecúmenos noctenes los que se encargan de hacer cruzar el río en chalana a los viajeros (Ercole, 1874d).

De esta manera, por el momento los franciscanos optan por otra medida, la misma que se tomó tras la fuga de los tobas de San Francisco en 1862: agregar neófitos chiriguanos a la misión. Al parecer una familia chiriguana ya vivía en San Antonio, adonde había llegado desde el cerro vecino del Pirapo (Dimeco, 1879). Pero se multiplican en 1874, con el arribo de los chiriguanos Yarecu y Arasayu "con todos sus soldados" desde el cerro y las misiones más norteñas: "Con estos chiriguanos quedaba asegurada la vida del P. conversor (Marcelleti, 1878i, f. 2).

En total son 120 chiriguanos del Pirapo y de Macharetí los que se instalan en San Antonio (Corrado, 1884, p. 481); probablemente a ellos se refiere la tradición oral weenhayek cuando alude a chiriguanos "llegados del cerro" (Alvarsson, 2012, pp. 39-40). El mismo relato agrega que pronto los chiriguanos empezaron a discutir con los noctenes por la tierra. De hecho, la decisión de los padres no hace más que empeorar las cosas:

Desde entonces empezó otra era para S. Antonio, era de confusión, riñas, sinsabores y división del corazón para el conversor, con dos naciones naturalmente enemigas y antipáticas. Los avas levantaron la cresta, porque se veían necesarios; los noctenes se veían con esto humillados, por su deserción y desconfianza del padre. El padre 
volvió su atención principal a los avas, tanto para los trabajos, rezo, escuelas, servicios, etc., como más nacionales; y los noctenes quedaron como agregados, esclavos de los avas y del padre (Giannecchini, 1879a, f. 6).

\section{La expulsión}

En el frente chiriguano, la derrota total de los indígenas en una épica batalla en enero de 1875 anuncia el fin de la guerra ${ }^{23}$. Si bien otros asaltos tienen lugar más tarde, los chiriguanos están heridos de muerte. Con la caída de sus principales aliados, los tobas cambian de táctica y muchos de ellos, buscando protección, manifiestan el deseo de reintegrarse a la misión de San Francisco. Los franciscanos les proponen un trato: aquellos que quieren volver estarán "a prueba" en la misión de San Antonio, y si se portan como es debido y dan muestras de un sincero arrepentimiento, se les volverá a admitir en San Francisco ${ }^{24}$

Entre 1876 y 1878 conviven así tres grupos étnicos -noctenes, tobas y chiriguanos- en San Antonio, exacerbándose las malas relaciones entre ellos. Si los noctenes no soportan a los chiriguanos recién llegados, tampoco "se avienen" con los tobas (Marcelleti, 1877a, f. 1v). Lo que sucede fuera del recinto misional entorpece aún más la situación. Los tobas que permanecieron en el Pilcomayo sin regresar a la misión, apoyados por no pocos chiriguanos que huyeron de las represalias, continúan asaltando haciendas criollas e incluso amenazan la misión de Macharetí. Más aún, ladrones y asesinos buscan asilo en la propia misión de San Antonio. En noviembre de 1876 el subprefecto del Gran Chaco denuncia que "hay [en la misión] muchas familias de tobas, notenes y tapietes, y varios capitanes que antes y ahora mismo viven del robo y el pillaje" (Subprefectura del Gran Chaco, 1876a); lo reitera en diciembre tras una expedición río abajo, en la que los mismos indígenas le confesaron "que los principales ladrones se encuentran asilados en su misión, con el objeto de sustraerse a la acción de los cristianos" (Subprefectura del Gran Chaco, $1876 \mathrm{~b})$. Seis meses después, los tobas de Teyu, río abajo, se van a refugiar a San Antonio para sustraerse a la venganza criolla (Subprefectura del Gran Chaco, 1877). En esta confusa situación, los noctenes de la misión están angustiados, indecisos. Varios piensan que los criollos vendrán a la misión en busca de los ladrones y los matarán a todos, otros piensan en abandonar San Antonio (Marcelleti, 1876, f. 2).

En 1878, los franciscanos renuncian a una misión imposible. Los tobas no cumplieron con sus promesas y, lejos de arrepentirse, continuaron robando y matando. Se decide expulsarlos definitivamente, lo que se hace el 3 de junio de 1878 (Giannecchini, 1878, 1880). Los chiriguanos

\footnotetext{
${ }^{23}$ Corrado, 1884, p. 481; Martarelli y Nino 1918/2006, pp. 64-65.

${ }^{24}$ Marcelletti, 1877b; Dimeco, 1878, f. 1. Combès, 2019b, cap. 3.
}

quieren aprovechar la ocasión para lograr la expulsión de los noctenes también, sin éxito (Giannecchini, 1878). La expulsión de los tobas no devuelve la calma a San Antonio. Los noctenes van y vienen más que nunca y, por momentos, "la misión de noctenes no era más que de nombre, de hecho era de los avas" (Giannecchini, 1879a, f. 10). En esta incertidumbre, el P. Marcelleti no se atreve a emprender nuevos trabajos (Marcelleti, 1878a). La misión sigue además amenazada por los rebeldes. En septiembre de 1878 chiriguanos neófitos de Tarairí y Macharetí hacen una expedición Pilcomayo abajo y vuelven con cautivos tobas y el saldo de una mujer y cuatro hombres tobas muertos (Marcelleti, 1878d). Esto hace presagiar venganza por parte de los tobas: "es propia del indio la venganza y ésta siempre sucede con el más débil. Y quién más débil que este pueblo" (Marcelleti, 1878 g, f. 1v). Marcelleti está desesperado por "la continua incertidumbre, la incesante irresolución de si vivirá o morirá esta reducción de noctenes" (Marcelleti, 1878c, f. 1v). De hecho, el otro peligro, no menos amenazante, es la complicidad de los noctenes de San Antonio con los tobas del Pilcomayo:

En estos días se ha descubierto que los noctenes estos tienen relación con los tobas del río abajo, que roban con ellos (Marcelleti, 1878e).

Lo positivo es que estos noctenes están de a buenas con los tobas (Marcelleti, 1878f).

Estos misioneros noctenes conservan mutuas relaciones con los salvajes tobas de los campos. De esta relación mutua resulta que los noctenes ayudan a ellos en los robos que cometen. De manera que la hacienda de esta misión no está segura, porque los tobas con toda seguridad se la llevan sin que nadie les estorbe. Antes bien hallan quienes les ayuden. Que sea así se arguye que los noctenes continuamente, con pretexto de ir a pesquear [sic], van río abajo como, cuando y conforme quieren (Marcelleti, 1878g, f. 1).

A finales de octubre la situación se vuelve tan alarmante que se habla de desocupar la misión si no se concreta la construcción de un nuevo fortín río abajo. La idea es trasladar al P. Marcelleti, los bienes de la misión y, si fuera posible, los catecúmenos noctenes, a San Francisco (Acta, 1878).

El malestar general es aprovechado por los chiriguanos de San Antonio, y todo parece mostrar que con la firme intención de deshacerse de los noctenes. Hacen correr voces contradictorias: los criollos vendrán a la misión y acabarán con todos los noctenes, o bien los franciscanos llamarán a los chiriguanos y botarán a todos los noctenes de la misión, etc. (Marcelletti, 1878h, f.1 y 1878j). Un mes después, "Ios avas no dejan de instigar a los noctenes", de ahí que los catecúmenos de San Antonio "ni piensan siquiera para [hacer] sus chacras" (Marcelleti, 1878h, f. $1 ; 1878 \mathrm{~m})$. 
De manera extraña las cosas parecen calmarse un poco a inicios de 1879 . Los niños noctenes, antes poco aficionados a la escuela (Marcelleti, 1878k), ya "se muestran más diligentes y constantes en asistir" en febrero y marzo de 1879 (Marcelleti, 1879a y 1879b). En estos meses, San Antonio cuenta con 150 familias noctenes que representan aproximadamente 600 personas; los chiriguanos son $93^{25}$. Entre los noctenes más mencionados están los jefes Catuna y Calata; Arrocito, aparentemente confidente del P. Marcelleti; y Rubio, probablemente mestizo dado su nombre. Su hijo Canolis es "alcalde" de la misión, junto con Yguetén, que tal vez sea un chiriguano casado con una noctén: de hecho, aparentemente los noctenes no lo quieren, y le exigen dar ponchos y demás cosas porque son parientes de su esposa. Otros nombres mencionados son Ynnes, su hija Nicolasa (bautizada, entonces), y Achova ${ }^{26}$.

Si bien Marcelleti parece optimista, otros no lo son tanto y en primer lugar Giannecchini, prefecto de misiones. La misión tiene 16 años de existencia, y en este lapso sólo 154 personas fueron bautizadas, de las que 130 murieron: la mayoría eran bebés, y uno que otro adulto bautizado in articulo mortis. En el mismo lapso de tiempo "ningún noctene adulto pidió de [sic] ser bautizado", y no se celebró ningún matrimonio religioso.

De esta manera, en abril de 1879 Marcelleti reúne a sus catecúmenos para reprenderlos y transmitirles el mensaje de sus superiores: si no cambian de actitud, la misión será abandonada. Los indígenas prometen enmendarse y, según su conversor, "así lo están haciendo" (Marcelleti, 1879b). Sin embargo, en junio, Giannecchini envía un cuestionario a los misioneros para pedir su opinión ${ }^{27}$. Y los padres son casi unánimes en sus respuestas. Primer punto, la misión nunca funcionó adecuadamente y sus neófitos nunca dieron prueba de fidelidad a los misioneros (Dimeco, 1879). Segundo punto, la conexión entre noctenes y tobas es demasiado fuerte: los noctenes son los "alcahuetes" de los tobas (Dimeco, 1879; Giannecchini, 1879a, f. 5). Tercer y último punto, está el problema de la convivencia con los chiriguanos, "sinceros aborrecedores de los noctenes y anhelosos por librarse de su compañía" (Giannecchini, 1879a).

De manera que la mayor parte de los frailes aboga por la expulsión de los noctenes y el abandono de la misión. Las excepciones son Nazareno Dimeco, para quien la Iglesia no puede desentenderse de los noctenes ya neófitos y bautizados (1879, f. 1v); y Vicente Marcelleti, que quiere creer todavía que sus catecúmenos "han mejorado en la vida civil-social [...] En los primeros años no se conseguía lograr bautizar enfermito alguno, porque sus padres lo ocultaban, y actualmente, o ellos mismos avisan al P.

\footnotetext{
${ }^{25}$ Giannecchini, 1879b, ff. 5-5v. Se trata de familias nucleares, según el modo de contar de los franciscanos.

${ }^{26}$ Ver especialmente Marcelleti, 1878 I, 1878 m y $1882 a$.

${ }^{27}$ El cuestionario de Giannecchini se encuentra en Dimeco, 1879.
}

conversor, o cuanto menos cierto que no lo ocultan" (Marcelleti, 1878i, f. 2).

Los indígenas mismos se encargan de zanjar el asunto: la noche del 2 al 3 de agosto de 1879, "todos los noctenes en cuerpo, rompiendo sus cántaros, chichas y maíz, dejándolo todo en la presencia y vista del padre, se mandaron a mudar toditos" (Giannecchini, 1879a, f. 11). Y la historia se repite:

A los 3 o 5 días de la fuga, que ellos achacaban a los avas de todas las misiones, especialmente de S. Antonio y S. Francisco, por los cuentos que les habían puesto, empezaron a volver de a 4, de a 10 , de a 15 , etc., menos los capitanes, diciendo haber sido sonsos y engañados por los avas, etc., que seguirían de misioneros por más que los padres no quisiesen (Giannecchini, 1879a, f. 11).

Demasiado tarde. Los franciscanos ya no creen en excusas y promesas. El 30 de agosto de 1879 firman el acta de supresión de la misión de San Antonio: y "así quedó definitiva y completamente suprimida y abandonada, la malograda, ingrata y desgraciada misión que fue de los noctenes" (Acta, 1879).

\section{Noctenes, güisnayes y tobas}

De manera oficial, tobas y noctenes están entonces fuera de las misiones. En la práctica la situación es bastante diferente y los indígenas siguen yendo y viniendo entre las misiones y sus tolderías. En octubre de 1878, cuatro meses después de su expulsión, varios tobas siguen apareciendo en San Antonio y, un año después, un informe indica que en la misión conviven noctenes, chiriguanos y tobas (Marcelleti, 1878g; Giannecchini, 1879c). Todavía en 1882 existen menciones de tobas y noctenes presentes en las reducciones (Rivas, 1882a). No se trata de una presencia permanente, pero demuestra que las "drásticas" medidas de los conversores quedaron sin efecto. Como bien dijeron los noctenes: "seguirían de misioneros por más que los padres no quisiesen".

Los años comprendidos entre 1878 y 1884 son de extrema violencia toba $\mathrm{y}$, por lo tanto, bien documentados al respecto: robos a haciendas y viajeros, asesinato de la tripulación del explorador Julio Crevaux, sangriento asalto a un convoy, rapto de una joven criolla, etc. En 1883, la expedición exploradora dirigida por Daniel Campos funda en Teyu, "capital" de los tobas, la colonia militar bautizada Crevaux.

Por el contrario, es poco lo que sabemos sobre los noctenes en estos años. Si bien pasan temporadas en las misiones, no están contabilizados por los frailes; a orillas del Pilcomayo, las noticias sobre los noctenes se mezclan con las de los tobas, lo que evidencia que los lazos entre ambos grupos siguen más fuertes que nunca; 
se advierten también relaciones con los güisnayes (es decir, 'weenhayek') de río abajo.

En abril de 1882 el afamado explorador francés Julio Crevaux emprende una nueva expedición fluvial al Pilcomayo. Su viaje dura apenas nueve días y, cerca de Cabayurepoti, la tripulación es asesinada por los indígenas tobas (Combès, 2017a). En el revuelo provocado por la matanza, si bien todos coinciden en culpar a los tobas, no faltan tampoco acusaciones contra otros grupos indígenas de la región y particularmente contra los noctenes y/o los güisnayes de río abajo. Los primeros en acusarlos son capitanes tobas, que afirman que "las muertes las habían hecho los noctenes capitanados [sic] por el capitán Silomi, quien vive en Piquirenda", porque años atrás los karai habían matado a su padre. Junto con Silomi también "ha estado Zacaría Tatiyuru noctén [...] la plata, los noctenes la han llevado a Itiyuru, ahí han comprado queso, charque, carne, etc. etc., etc. Las armas las tienen los noctenes en Piquirenda" (Marcelleti, $1882 b$, f. 1).

Llama la atención la alusión a noctenes en Piquirenda, epicentro del territorio de los güisnayes, cuyo nombre no es sino una grafía de "weenhayek". "Célebre", "renombrado y prestigioso", Silomi o Sirome es en esta época el gran jefe de los güisnayes, y su autoridad es acatada "por muchas tribus al sud y norte de su residencia habitual" (Campos, 1888, pp. 112-113, 123).

No sabemos si son los tobas o, más probablemente, Marcelleti quienes califican aquí de "noctenes" a los güisnayes. En todo caso, la asimilación hecha entre ellos parece reveladora de la existencia de fuertes lazos entre ambos grupos. Ya Magariños y Van Nivel habían proporcionado indicios en este sentido. A fin de siglo, Giannecchini afirma que los "guisnais" "son de la misma familia que nuestros noctenes y aún emparentados con ellos" (En Lafone Quevedo, 1897, p. 53). Una década más tarde, se comprueba también la presencia de "güisnayes" (concretamente, de Achicoria, el hijo mayor de Sirome) en la Colonia Crevaux, es decir en pleno territorio noctén ${ }^{28}$.

En agosto de 1882 los tobas reiteran sus acusaciones contra los noctenes: "contestaron [...] que los que habían asesinado a Crevaux habían sido los noctenes capitaneados por Tatuyuruy Blanco, quienes actualmente se hallaban en Ytiyuru; que los habían muerto un poco más arriba de Piquirenda" (Giannecchini, 1883/2006b, p. 650). Según el subprefecto del Gran Chaco, los tobas explicaron también que habían rescatado al único sobreviviente de la masacre de las garras de estos noctenes, para devolverle a la misión de San Francisco (Subprefectura del Gran Chaco, 1882, p. 2).

\footnotetext{
${ }^{28}$ Fotografía de Jean-Baptiste Vaudry (1903) en Combès y Salaun (eds.) 2018: fig. 76.
}

Un mes después aparecen en San Francisco curiosas medallas que algunos tobas intercambian con los chiriguanos a cambio de víveres, y son identificadas por los frailes como monedas pertenecientes a los viajeros asesinados (Giannecchini, 1883/2006b, p. 653). Pero en la versión del viajero francés Arthur Thouar (1884, p. 230), los que las quieren intercambiar por maíz y tabaco son en realidad noctenes. Por último, dos años después de la masacre, un supuesto testigo afirma que dos de los tripulantes de Crevaux lograron huir río abajo, pero fueron capturados y matados por los "noctenes y matacos" de la ribera derecha del río (Thouar, 1899, p. 22).

Ninguna de estas acusaciones logra probarse, y ninguna es contundente. Gente y cosas viajan mucho en el Chaco indígena, y las pertenencias de Crevaux siguieron sin duda los mismos caminos. Los que más insisten en la culpabilidad noctén son, además, los tobas, es decir los principales sospechosos. Tampoco queda claro si acusan a los noctenes stricto sensu, a los güisnayes o a otros "matacos". Lo más relevante del asunto es, sin duda, la asimilación que parece hacerse entre noctenes y güisnayes y, una vez más, la asociación real o imaginada de los noctenes con los tobas. De hecho, también aparecen juntos pocos meses después, en septiembre de 1882, cuando un mestizo chiriguano-toba de nombre Socó es asesinado cerca de Tarairí por militares criollos. Socó estaba acompañado por una decena de tobas en este confuso incidente, aunque algunas fuentes también hablan de la presencia de noctenes (Rivas, 1882b; Stazi, 1882). Por último, las noticias de noviembre del mismo año 1882 también juntan tobas con noctenes. Todas son relativas a una nueva expedición al Pilcomayo, esta vez terrestre, dirigida por Andrés Rivas.

La expedición sale de Caiza el $1^{\circ}$ de octubre, hasta Santa Bárbara, en la ribera derecha del Pilcomayo. Ahí, la comisión Rivas empieza los preparativos para establecer una colonia militar (Giannecchini, 1882/2006a, pp. 592, 595), y sabemos que varios noctenes se presentan para servir en los trabajos (Rivas, 1882c). Pero muy poco después empiezan los problemas. El 3 de noviembre varios soldados trabajan en abrir una senda. Un grupo de tobas los ataca, roba nada menos que 250 animales y mata a cuatro personas. Abrumado y furioso, Rivas declara una "guerra de exterminio" a los tobas (Giannecchini, 1882/2006a, pp. 604-605). El 6 de noviembre, llegan a Santa Bárbara un grupo de 14 tobas acompañados por un noctén apodado el Rengo, anunciando que quieren entregar algunas mulas de la tropa que se perdieron días antes. Rivas quiere apresar a los indígenas, pero sus soldados se adelantan y abren el fuego. Sigue una confusa pelea con los tobas defendiéndose, los soldados disparando a diestra y siniestra y matándose entre sí, que acaba con el saldo de siete soldados y los 14 tobas muertos, y el retorno inmediato de los exploradores a Caiza (Giannecchini, 1882/2006a, pp. 607-608). 


\section{San Antonio agoniza}

Los meses siguientes hasta 1884 no ofrecen más noticias sobre los noctenes, pero sí sobre los tobas. En noviembre de 1883, el jefe Cuserai es salvajemente asesinado en la flamante Colonia Crevaux por los soldados criollos (Anales 1883/2006, pp. 1250-1251; Giannecchini, 1883). Dos meses después, en enero de 1884, los tobas ejecutan una doble venganza: por la muerte de Cuserai, y por la de Socó. El jefe Taicoliqui, único sobreviviente de la masacre de la Colonia Crevaux, el hermano de Socó y otros líderes asaltan un convoy que se dirige de Caiza hasta la Colonia Crevaux. Roban víveres, caballos, armas y dinero, y asesinan a todos los viajeros a excepción de dos: Cecilia Oviedo, una joven criolla de Caiza, y su hermano Manuel, que son capturados (Oviedo, 1884; Combès, 2017b).

Tras seis meses de negociaciones, la joven y su hermano finalmente son entregados a los franciscanos, a cambio de un jugoso botín y, sobre todo, en señal de paz: acosados por las incesantes correrías vengativas de los criollos, los tobas se muestran deseosos de firmar un nuevo tratado con los blancos. Este tratado, que finalmente se firma en septiembre de 1884, involucra además a otros grupos étnicos del Chaco boliviano: tapietes, chorotes y noctenes. Los noctenes que suscriben el tratado son Caelaeta [Calata] de Irua, calificado en el documento de "capitán grande"; Catuna, también de Irua; Camachiliqui de Yuquirenda y Nocpella de Yanduñanca (Tratado, 1884). Al menos los dos primeros aparecen en fuentes anteriores, como catecúmenos de San Antonio. Más tarde, Calata sigue siendo el "rey o gran jefe" de los noctenes de la misión (Giannecchini, 1898/1996, p. 187).

De hecho, una consecuencia casi inmediata del tratado es el retorno del rebaño de los neófitos noctenes y tobas a sus respectivas misiones (Giannecchini, 1885). Entre los noctenes que regresan figuran los moradores de Yuquirenda, refugiados río abajo entre los güisnayes - una muestra más de los estrechos lazos entre ambos grupos (Giannecchini, 1884).

En total son como 600 personas que de nuevo están reunidas en San Antonio, ocupando 130 casas (Anales 1884/2006, p. 1253), y los franciscanos deciden reabrir oficialmente la misión (Pifferi, 1885). Al año, el número de catecúmenos sube levemente: 100 familias, con 665 personas, de las cuales 650 son "infieles" (Giannecchini, 1885). Según el delegado del gobierno Manuel Othon Jofré, la misión se vuelve a inaugurar solemnemente el 19 de mayo de 1887 (Jofré, 1895/2006, p. 476).

Pero estos prometedores (re)inicios pronto quedan en nada, y la situación vuelve a estancarse. Los indígenas son tan andantes como antes, "raza rebelde a la educación y a las costumbres cristianas y civilizadas, pegada a su vida errante y selvática":
Los indios noctenes llegan a la misión cuando sus necesidades lo exigen, para ser alimentados y amparados por ella, pero fugan a los montes y bosques robando de las escuelas a sus hijos, tan luego como el algarrobo o los frutos y raíces silvestres pueden darles algún alimento, de manera que esta misión se renueva casi incesantemente: se apegan a ellas familias acosadas por sus necesidades y emprenden la fuga las que se han satisfecho (Jofré, 1895/2006, p. 477).

Según la misma autoridad, estos "idiotas" son "flojos y desidiosos", además de sucios. Se niegan a criar vacas, a lo sumo algunas ovejas, tampoco quieren sembrar mucho.

Los postreros años del siglo no mejoran la situación. El mundo de los noctenes y, más allá, de todos los indígenas del Pilcomayo, va cambiando. Los colonos empiezan a avanzar río abajo, protegidos por la Colonia Crevaux y, a partir de 1890, del nuevo fortín Murillo. Tal como hicieran años antes en Bella Esperanza, los indígenas instalan sus tolderías cerca de estos centros y comercian con los soldados. En la misma época las migraciones estacionales a los ingenios azucareros del noroeste argentino, iniciadas a pequeña escala años antes, toman una creciente importancia. Son miles los indígenas de Bolivia que se dirigen a la Argentina con la esperanza de ganar algo de dinero, o un poco más de libertad. Entre ellos, los chiriguanos y los "matacos" son los más numerosos ${ }^{29}$.

Estas migraciones desangran las misiones chiriguanas, que ven mermar su número de neófitos. A este sombrío panorama se suma, para los franciscanos, el clima liberal y anticlerical que toma fuerza en Bolivia en este fin de siglo.

De esta manera el papel de la misión va menguando. Paulatinamente, el número de catecúmenos disminuye: 531 en $1893^{30}$, que se reducen a 260 en $1899^{31}$. La inasistencia y la apatía de los noctenes siguen exasperando a los frailes, que en 1897 deciden tomar "medidas enérgicas" para "ponerlos al nivel de los chiriguanos" (Costa, 1897).

Pero uno de los problemas más álgidos es, precisamente, la convivencia de los noctenes con los odiados chiriguanos, y lo mismo pasa con los catecúmenos tobas en la otra banda del río. Así por ejemplo, en 1894, por alguna desavenencia con los chiriguanos, tobas y noctenes retiran a sus hijos de la escuela misional (Cuadro sinóptico, 1894). La situación es tan tensa que tobas y

\footnotetext{
29 Langer, 2009, pp. 114-117. Según datos del autor, el ingenio La Esperanza empleaba hasta 2.000 indígenas en tiempos de zafra en 1904; en 1914 60\% de sus trabajadores eran chiriguanos, 35\% matacos y el resto dividido entre tobas e indígenas andinos.

30 Jofré, 1895/2006, p. 478. Del total 431 son infieles, 66 neófitos y catecúmenos, y 34 bebés.

${ }^{31}$ Anales 1899/2006, p. 1326 (53 familias infieles, con 260 personas).
} 
noctenes empiezan a reclamar una misión propia. "Los feroces tobas y fríos noctenes o matacos [...] esperan impacientes, especialmente los primeros, el momento feliz de ver fundada una misión río abajo, entre los suyos y para ellos exclusivamente" (Anales 1892/2006, p. 1318).

Empieza así una larga serie de trámites para poder lograr la fundación de dos nuevas misiones en el Pilcomayo (Pifferi, 1892; Dimeco, 1894). Sin embargo, ninguna de ellas se hace realidad. La razón siempre repetida es la falta de misioneros disponibles (Costa, 1885, 1896a).

El tedio vuelve a dominar San Antonio. Con nuevos centros de atracción y más recalcitrantes que nunca al bautismo, los noctenes empiezan a desertar paulatinamente de la misión. En agosto de 1899, el P. Marcelleti informa que casi todos abandonaron la reducción, de nuevo por rumores esparcidos por los chiriguanos sobre la pronta llegada de soldados para matarlos (Marcelleti, 1899). Como siempre, la mayor parte de los indígenas empieza a regresar a los pocos días. Pero tanto noctenes como franciscanos se cansaron de jugar al escondite. Un año después de la fuga, el prefecto de misiones no se hace más ilusiones y declara que "en cuanto a los noctenes o matacos, no tenemos mucho que esperar"; los que han vuelto "serán siempre lo que han sido, esto es, gente sensual y abyecta, desleal e insegura" ${ }^{2}$.

El nuevo misionero de los noctenes es Inocencio Massei, que llega a arriesgar varias veces su vida en su apostolado: "tanta es la aversión que tienen al santo bautismo que a este último Padre le han impedido la entrada a sus chozas con el cuchillo en la mano, y aun lo han amenazado y perseguido con tizones de fuego"; en otra ocasión un catecúmeno entra a su habitación y casi lo mata (Ducci, 1895, p. 28). De esta forma, cuando en 1905 el gobierno de Ismael Montes seculariza las dos misiones de San Francisco y San Antonio para crear la flamante Villa Montes, ambas están casi vacías de sus habitantes tobas y noctenes (Combès, 2019a).

\section{Apatía y buena voluntad}

El casi medio siglo de existencia de la misión de San Antonio es el periodo mejor documentado de la historia de los noctenes. Una historia que las fuentes escritas (por otros, siempre) retrata como apagada, pasiva, en la que los noctenes son simples cómplices o "alcahuetes" de los tobas: una historia a la sombra de los tobas. Los noctenes parecen actuar como un grupo toba más y, de hecho, son numerosos los testimonios que los califican de "parientes" de los tobas, de "semi-tobas", etc. Los actuales weenhayek también hablan mucho de "cruces", es decir de casamientos interétnicos, con los tobas (Alvarsson, 2012: 61). No podemos atribuir esta situación

\footnotetext{
${ }^{32}$ Nota del P. Costa, noviembre de 1901, en Calzavarini (ed.), 2006 t. VII, pp. 2144-2145.
}

a una mayor convivencia entre ambos grupos en la misión franciscana: ya en 1860, a vísperas de la fundación de San Francisco, noctenes y tobas esperan juntos ingresar a la misión.

Sin embargo, las relaciones matrimoniales de los noctenes con los tobas (y con otros grupos) parecen desarrollarse en un solo sentido: mujeres noctenes con hombres tobas o chiriguanos, incluso criollos, y casi nunca al revés. En este sentido van los pocos ejemplos registrados en las fuentes (p. ej. Marcelleti, 1878k); en este sentido también van las observaciones de John Palmer acerca de los wichís actuales (2005, 156). En la guerra como en la alianza, los noctenes aparecen como un "sub" grupo toba en todos los sentidos del término: un grupo en situación subordinada, o menos importante, que a lo sumo ayuda, favorece los robos, no denuncia, pero no va más allá. Los noctenes son "criados ayudantes" de los tobas, dice Giannecchini $(1879$, f. 5); si algo hacen, remata Marcelleti, es juntamente con los tobas y de ocultas, "porque no son capaces de presentarse a cara descubierta" (1878i, f. 2).

Es incluso frecuente que los criollos, incapaces de observar las diferencias, los confundan con los tobas. Ya para Magariños y Weddell, tobas y noctenes tienen las mismas costumbres y hablan el mismo idioma (Magariños 1844 30.04.1844, p. 2; Weddell 1851/2018, pp. 125, 243). En 1882, pocos días antes de su asesinato, Crevaux afirmaba haber acordado la paz con "los tobas", cuando estuvo hablando en realidad con noctenes de Irua (Giannecchini 1883/2006b, p. 643); si bien el error es comprensible por parte de un extranjero recién llegado, Crevaux estaba acompañado por varios criollos de Caiza, que aparentemente no repararon en el equivoco. Otro ejemplo de lo mismo es el libro de Amadeo Baldrich (1890), cuyos capítulos XII y XIII están respectivamente dedicados a "Ios matacos" y "los tobas": en este último apartado figuran los noctenes.

Más cercanos a sus catecúmenos, aprendiendo sus lenguas incluso, los franciscanos no cometen tales errores. Pero cuando describen a los noctenes, siempre es en el mismo registro: Corrado habla de su "natural apatía" (1884, p. 479), Gervasio Costa los describe como una nación "fría, glacial e indiferente de todas [...] lo hacen todo con una apatía increíble" (Costa, 1900). En cuanto a Marcelleti, el misionero que probablemente mejor los conoce, escribe a Giannecchini:

La nación noctene es demasiado abatida, prostrada, dejada (y todo esto hay que tenerlo bien presente en cualquier circunstancia y en todo asunto nocteno), de nada se le da. Todo su bienestar lo hace consistir en el afán de buscar cada día de qué mantenerse, sean raíces de la tierra, sean frutas silvestres, sean pescados, etc., etc. Del resto a nada aspira ni a tener siquiera un palo para cabecera. Y siendo así la nación, 
no puede tener en sí misma sino una vida débil y lánguida, una vida que apenas se percibe [...] Por sí misma la nación noctena es desidiosa y floja (Marcelleti, 1878i, f. 1).

Los chiriguanos pueden ser inconstantes o pérfidos; los tobas oscuros, insolentes, traidores. Todos son guerreros, todos son temidos. Pero los noctenes no. Ni siquiera son pacíficos, sino "cobardes" o "pusilánimes" (Corrado, 1884, p. 418). Los padres reconocen, sin embargo, que en caso necesario los noctenes saben defenderse y bien, pero "por sí mismo él no provoca a nadie"; y se repite, una vez más, que si el grupo entra en guerra, "es por las insinuaciones y empujes de la guerrera tribu de los tobas que son sus parientes y vecinos" (Giannecchini, 1898/1996, p. 386).

Influye por cierto en esta letanía siempre repetida la escala de valores de criollos bolivianos y frailes italianos, que privilegia el sedentarismo, la práctica agrícola y, en suma, todo lo parecido a la civilización occidental, por encima de un nomadismo incomprensible. Más aún, criollos y franciscanos conocieron a los noctenes a través de los chiriguanos, que por su parte hacen alarde de un marcado etnocentrismo hacia los habitantes del Chaco; el chiriguano, recalca Giannecchini, "se considera miembro de una raza nobilísima con respecto a las demás tribus que desprecia", porque ignoran el arte de sembrar maíz (Giannecchini, 1898/1996, p. 296). Los colonizadores adoptaron a rajatabla estas representaciones que coincidían con las suyas propias. Pero el etnocentrismo exacerbado de los chiriguanos y los valores occidentales, que se refuerzan mutuamente, no bastan para explicar la peculiar percepción de los noctenes que impera en la época y en nuestras fuentes. Los tobas por ejemplo también son salvajes, también son sucios y sarnosos: "pero los noctenes están llenos de sarna, son los dueños de la sarna", dicen los chiriguanos (Giannecchini et al. 1916, pp. 33-34). Los tobas son temidos y respetados por su valentía; los noctenes llevan "marcada en su faz la estupidez selvática" (Jofré, 1895/2006, p. 476).

Lo que las fuentes decimonónicas llaman apatía o desidia es calificado de "predisposición apacible" de los wichís por Palmer (2005, p. 6), e interpretado por él a partir del concepto central de husék, un término que el autor traduce por 'voluntad' o mejor dicho 'buena voluntad'. Escribe Palmer:

La violencia es contraria a la vida humana porque el bienestar colectivo depende de la armonía social [...] la falta de agresión viene a ser, pues, el primer criterio para tener en cuenta al esbozar la buena voluntad wichí [...] la concepción ideal de la persona wichí [es la de un] ser apacible e impasible, ratificando así el criterio de la buena voluntad como valor cultural principal [...] para los Wichí, la operancia colectiva de la buena voluntad se evidencia en la armonía social, cuyo aspecto concreto es la quietud (2005, pp. $6,34,37)$.

La mirada del antropólogo revela la otra cara de la moneda, un valor positivo puesto al servicio de la comunidad, ahí donde frailes y demás vieron una tara insuperable o un defecto congénito. La "buena voluntad wichí ciertamente permite entender la resistencia pasiva, amorfa, sin brillo ni grandes batallas, de los noctenes. Una resistencia dirigida, además, tanto contra los blancos (misioneros, militares, colonos) como contra los indígenas vecinos: los chiriguanos, con quienes la convivencia es difícil pero no desemboca nunca en una guerra abierta; y los tobas también, "parientes" a quienes no se niega un apoyo sin embargo siempre pasivo, nunca demasiado comprometido, y sin que por ello las relaciones sean más amigables:

Amigos de los padres, pero no misioneros: amigos de los avas, pero por sus comercios; amigos y alcahuetes de los tobas con sus conveniencias, amigos de los carais para venir a atisbar con más seguridad y dar parte a los tobas de los puestos y posesión de los cristianos; seguir a engañar a todo el mundo con su apatía y zorrería y nada más! (Giannecchini, 1879a, f. 14).

$$
* * *
$$

Ante la actual invasión y depredación del territorio wichí, ante los múltiples problemas culturales y sociales vividos por los wichís contemporáneos, Palmer se pregunta:

¿De qué les sirve a los Wichí su buena voluntad frente al avance de la globalización avasalladora? [...] La resistencia que oponen al fenómeno social que los amenaza se manifiesta a través de la paciencia y la tolerancia, expresiones de buena voluntad [...] Su propia ética de la buena voluntad facilita así el quehacer de los agentes de destrucción ambiental y cultural $(2005$, p. 8).

Sin embargo, llámese apatía o husék, zorrería o apacibilidad, en el siglo XIX la resistencia noctén fue una estrategia efectiva. Los fieros chiriguanos acabaron humillados, en estado de semi-esclavitud en las haciendas criollas; los temibles tobas tuvieron que abandonar el territorio boliviano y refugiarse en la Argentina. Los noctenes no. Explotación ciertamente hubo, pero preservaron su territorio. Hoy los weenhayek siguen viviendo firmes a orillas del Pilcomayo, y los estigmas que continúan sufriendo por parte de la sociedad envolvente sólo logran subrayar su alteridad más absoluta, la que les permitió sobrevivir como "pueblo diferente".

Santa Cruz de la Sierra, 20 de septiembre de 2020 


\section{Bibliografía}

\section{Abreviaciones}

AFT Archivo Franciscano de Tarija

AN Archives Nationales (París, Francia)

Acta. (1878). Acta prefectural acerca de la crítica circunstancia que vive la misión de San Antonio, 27.10.1878. AFT 1-881.

Acta. (1879). Acta de la supresión de la malograda misión de San Antonio de Padua de los noctenes, 30.08.1879. AFT 2-901.

Alvarsson, J.-A. (1988). The Mataco of the Gran Chaco: An Ethnographic Account of Change and Continuity in Mataco Socio-Economic Organization. Uppsala: Acta Universitatis Upsaliensis vol. 11.

Alvarsson, J.-Å. (2012). Etnografía 'weenhayek, vol. 2: 'Nuestro Camino' - Etnohistoria e historia. Uppsala: Universidad de Uppsala/FI'WEN.

Anales. (2006). "Anales de este Colegio Franciscano de Tarija, 1879-1937". En L. Calzavarini (ed.). Presencia franciscana y formación intercultural en el sudeste de Bolivia según documentos del archivo franciscano de Tarija 1606-1936. Tarija: Centro Eclesial de Documentación, tomo VI, 1235-1484.

Baldrich, J. A. (1890). Las comarcas vírgenes. El Chaco central norte. Buenos Aires/La Plata: Jacobo Peuser.

Bossert, F. (2012). "Notas sobre la jerarquía interétnica en los ingenios azucareros del noroeste argentino". En D. Villar e I. Combès (eds.). Las tierras bajas de Bolivia: miradas históricas y antropológicas. Santa Cruz: El País/ Museo de Historia de la UAGRM, 217-236.

Calzavarini, L. (Ed.). (2006). Presencia franciscana y formación intercultural en el sudeste de Bolivia según documentos del archivo franciscano de Tarija, 16061936, tomos IV a VII: Época republicana. Tarija: CED.

Campos, D. (1888). De Tarija a la Asunción. Expedición boliviana de 1883, Buenos Aires: Jacobo Peuser.

Claesson, K. (2008). Notas sobre el vocabulario 'weenhayek. Cochabamba: Sociedad Bíblica Boliviana.

Combès, I. (2015). "Filtros étnicos en la historiografía indígena del Chaco boliviano". En P. García Jordán (ed.). El mundo latinoamericano como representación, siglos XIX$X X$. Barcelona: UB / Taller de Estudios e Investigaciones Andino-Amazónicos / Instituto Francés de Estudios Andinos, 17-36.

Combès, I. (2017a). ¿Quién mató a Crevaux? Un asesinato en el Pilcomayo en 1882. Santa Cruz de la Sierra: El País/ CIHA.

Combès, I. (2017b). "Un rescate chaqueño". Indiana, $34(2), 265-285$.

Combès, I. (2019a). El Delegado y sus caciques. Leocadio Trigo en el Chaco boliviano (1904-1909). Cochabamba: Itinerarios.

Combès, I. (2019b). Hijos del Pilcomayo. Los últimos tobas de Bolivia. Cochabamba: Itinerarios.

Combès, I. (2019c). "Diario de un idiota. La exploración del río Pilcomayo por Enrique van Nivel (Bolivia, 1844)". Revista del Museo de Antropología, 12 (2): 93-100.

Combès, I., Salaun M. (Eds.). (2018). El Chaco de JeanBaptiste Vaudry. Sucre: ABNB.

Cortez, G. (2006). "Cambios sociales y culturales en el pueblo indígena weenhayek en los últimos cincuenta años". En I. Combès (coord.). Definiciones étnicas, organización social y estrategias políticas en el Chaco y la Chiquitanía. Lima/Santa Cruz: IFEA- El País - SNV, 163-177.

Corrado, A. (1884). "Continuación de la historia del Colegio Franciscano de Tarija". En A. Comajuncosa, A. Corrado. El Colegio franciscano de Tarija y sus misiones. Noticias históricas recogidas por dos misioneros del mismo Colegio. Quaracchi: Tip. del Colegio de San Buenaventura, 279-503.

Costa. G. (1895). Carta al P. Dimeco, 22.05.1895. AFT 1-547.

Costa. G. (1896a). Carta al P. Dimeco, 18.12.1896. AFT 1-924.

Costa. G. (1896b). Carta al prefecto de misiones, 18.12.1896. AFT 1-924.

Costa. G. (1897). Carta al P. Turbessi, 26.02.1897. AFT 1-549.

Costa. G. (1900). Carta al arzobispo de La Plata, 22.08.1900. AFT 2-784.

Cuadro sinóptico. (1894). Cuadro sinóptico de las escuelas existentes en las misiones de infieles del Colegio de Tarija, 10.04.1894. AFT 2-838.

Dimeco, N. (1878). Respuesta al P. Giannecchini, 25.01.1878. AFT 1-2377.

Dimeco, N. (1879). Carta al P. Giannecchini, 5.06.1879. AFT 2-155. 
I. Combès | Revista del Museo de Antropología 13 (3): 379-394 | 2020 DOI: http://doi.org/10.31048/1852.4826.v13.n3.30365

Dimeco, N. (1894). Solicitud de adjudicación de terrenos para la fundación de una misión entre los noctenes, 8.02.1894. AFT 1-2717.

Documentos. (1863). Documentos sobre la fundación de la misión de San Antonio, 6.08.1863. AFT 1-819.

Ducci, Z. (1895). Diario de la visita a todas las misiones existentes en la República de Bolivia - América meridional, practicada por M. R. P. Sebastián Pifferi. Asís: Tip. de la Porciúncula.

Ercole, A. (1871). Carta a los PP. misioneros, 18.01.1871. AFT 2-3645.

Ercole, A. (1874a). Carta al P. Guardián y Discretorio, 2.01.1874. AFT 2-185.

Ercole, A. (1874b). Carta al P. Guardián y Discretorio, 14.02.1874. AFT 2-186.

Ercole, A. (1874c). Carta al P. Giannecchini, 3.10.1874. AFT 1-926.

Ercole, A. (1874d). Carta al prefecto de Tarija, 4.11.1874. AFT 1-2350.

García Jordán, P. (2001). Cruz y arado, fusiles y discursos. La construcción de los Orientes en el Perú y Bolivia, 18201940. Lima: IFEA/IEP.

Gianelli, J. (1860). Carta al P. Guardián y Discretorio, 1860. AFT 1-1959.

Gianelli, J. (1861). Circular a los PP. conversores, 23.02.1861. AFT 2-3624.

Gianelli, J. (1863). Relación de la exploración del Pilcomayo y fundación de San Antonio, 1863. AFT 2-912.

Gianelli, J. (1864). Vocabulario Mataco - Lengua Mataca, 1.01.1864. AFT 1-1869.

Giannecchini, D. (1874). Carta al P. Ercole, 3.10.1874. AFT 1-926.

Giannecchini, D. (1878). Carta al P. Guardián y Discretorio, 12.06.1878. AFT 1-880.

Giannecchini, D. (1879a). Añadidura a los apuntes para los anales de 1879. AFT 1-886.

Giannecchini, D. (1879b). Informe, 27.05.1879. AFT 1-888.

Giannecchini, D. (1879c). Cuadro sinóptico bienal de las misiones del Colegio de Tarija, 28.11.1879. AFT 2-819.
Giannecchini, D. (1880). Apuntes para los anales de 1880. AFT 1-892.

Giannecchini, D. (1883). Recuerdos de la Colonia Crevaux. AFT 1-913.

Giannecchini, D. (1884). Carta al coronel Estenssoro, 12.11.1884. AFT 1-876(100).

Giannecchini, D. (1885). Memoria, 19.04.1885. AFT 1-927.

Giannecchini, D. (1996). Historia natural, etnografía, geografía, lingüística del Chaco boliviano [1898]. Tarija: FIS/CED.

Giannecchini, D. (2006a). "Diario del viaje del Padre Doroteo Giannecchini, capellán castrense de la expedición terrestre al Chaco central en 1882". En L. Calzavarini (ed.). Presencia franciscana y formación intercultural en el sudeste de Bolivia según documentos del archivo franciscano de Tarija 1606-1936, tomo V. Tarija: CED, 583-624.

Giannecchini, D. (2006b). "Relación de lo obrado por los Padres misioneros del colegio de Tarija en las dos expediciones fluvial y terrestre al Pilcomayo del año de 1882" [1883]. En L. Calzavarini (ed.). Presencia franciscana y formación intercultural en el sudeste de Bolivia según documentos del archivo franciscano de Tarija 1606-1936, tomo V. Tarija: CED, 625-666.

Giannecchini, D., S. Romano y H. Cattunar. (1916). Diccionario chiriguanolespañol y español/chiriguano. Tarija: s/e.

Groff Greever, J. (1987). José Ballivián y el oriente boliviano. La Paz: Siglo Ltda.

Jofré, M. O. (2006). "Colonias y misiones. Informes de la visita practicada por el delegado del Supremo Gobierno" [1895]. En L. Calzavarini (ed.). Presencia franciscana y formación intercultural en el sudeste de Bolivia según documentos del archivo franciscano de Tarija 1606-1936. Tomo IV. Tarija: CED, 453-533.

Karsten, R. (1913). "La religión de los indios mataconoctenes de Bolivia". Anales del Museo Nacional de Historia Natural de Buenos Aires, 24: 199-218.

Lafone Quevedo, S. A. (1897). "Introducción". En J. Pelleschi. Los indios matacos y su lengua. Buenos Aires: La Buenos Aires, 3-66.

Langer, E. (2009). Expecting Pears from an Elm Tree. Franciscan Missions on the Chiriguano Frontier in the Heart of South America, 1830-1949. Durham: Duke Press University. 
Magariños, M. R. (1844). "Diario de la navegación y reconocimiento del río Pilcomayo". Gaceta del Gobierno, 23.04.1844: 1-2; 25.04.1844: 2-3; 27.04.1844: 2-3; 30.04.1844: 2-3; 2.05.1844: 2-3; 4.05.1844: 2-3; 7.05.1844: 3-4; 9.05.1844: 2-3; 11.05.1844: 1-2; 14.05.1844: 2-3.

Marcelleti, V. (1876). Notas sobre la misión de San Antonio, 22.11.1876. AFT 2-3468.

Marcelleti, V. (1877a). Carta al P. Mariani, 9.02.1877. AFT 2-598.

Marcelleti, V. (1877b). Carta al P. Mariani, 5.03.1877. AFT 2-599.

Marcelleti, V. (1878a). Carta al P. Giannecchini, 10.03.1878. AFT 2-586.

Marcelleti, V. (1878b). Carta al P. Giannecchini, 9.04.1878. AFT 2-587).

Marcelleti, V. (1878c). Carta al P. Giannecchini, 4.09.1878. AFT 2-585.

Marcelleti, V. (1878d). Carta al P. Giannecchini, 16.10.1878. AFT 2-591.

Marcelleti, V. (1878e). Carta al P. Giannecchini, 16.10.1878. AFT 2-583.

Marcelleti, V. (1878f). Carta al P. Giannecchini, 16.10.1878. AFT 2-590.

Marcelleti, V. (1878g). Carta al P. Giannecchini, 26.10.1878. AFT 2-592.

Marcelleti, V. (1878h). Carta al P. Giannecchini, 8.11.1878. AFT 2-589.

Marcelleti, V. (1878i). Carta al P. Giannecchini, 16.11.1878. AFT 2-616.

Marcelleti, V. (1878j). Carta al P. Giannecchini, 5.12.1878. AFT 2-593.

Marcelleti, V. (1878k). Carta al P. Giannecchini, 12.12.1878. AFT 2-594.

Marcelleti, V. (1878I). Carta al P. Giannecchini, 19.12.1878. AFT 2-595.

Marcelleti, V. (1878m). Carta al P. Giannecchini, 25.12.1878. AFT 2-596.

Marcelleti, V. (1879a). Carta al P. Giannecchini, 13.02.1879. AFT 2-609.
Marcelleti, V. (1879b). Carta al P. Giannecchini, 8.03.1879 (AFT 2-612

Marcelleti, V. (1879c). Carta al P. Giannecchini, 5.04.1879. AFT 2-614.

Marcelleti, V. (1882a). Carta al P. Giannecchini, 24.04.1882. AFT 2-578.

Marcelleti, V. (1882b). Carta al P. Giannecchini, julio de 1882. AFT 2-617.

Marcelleti, V. (1899). Carta al P. Costa, 9.08.1899. AFT 2-147.

Martarelli, A., B. De Nino. (2006). El Colegio franciscano de Potosí y sus misiones en el Chaco. Noticias históricas recogidas por dos misioneros del mismo Colegio [1918]. Cochabamba: Kipus.

Montani, R., I. Combès. (2018). "Etnonimia wichí: cien hipótesis para mil y un nombres". Revista Andina, 56: 227-269.

Nercesian, V. (2013). "Bases lingüísticas y sociohistóricas del estudio dialectal del wichi/weenhayek". VII Congreso de Estudios Bolivianos, Sucre, 29/07-1/08.2013.

Ortiz Lema, E. (1986). Los mataco noctenes de Bolivia. La Paz/Cochabamba: Los Amigos del Libro.

Oviedo, C. (1884). "Un rescate". El Trabajo, Tarija, 29.07.1884: 2-4

Palmer. J. H. (2005). La buena voluntad wichí: Una espiritualidad indígena. Buenos Aires: Grupo de trabajo Ruta 81.

Pifferi, S. (1885). Carta al prefecto de Tarija, 30.09.1885. AFT 1-876(117).

Pifferi, S. (1892). Solicitud al ministro de Gobierno y Colonización, 9.11.1892. AFT 2-274.

Rivas, A. (1882a). Carta al P. Giannecchini, 4.09.1882. AFT 1-2473.

Rivas, A. (1882b). Carta al P. Stazi, 10.09.1882. AFT 1-917.

Rivas, A. (1882c). Carta al P. Orsetti, 31.10.1882. AFT 1-921.

Subprefectura del Gran Chaco. (1876a). Carta al prefecto de misiones, 22.11.1876. AFT 1-2359.

Subprefectura del Gran Chaco. (1876b). Carta al P. Giannecchini, 23.12.1876. AFT 1-2361. 
Subprefectura del Gran Chaco. (1877). Carta al P. Mariani, 12.06.1877. AFT 1-2363.

Subprefectura del Gran Chaco. (1882). "Carta al prefecto de Tarija, 5.08.1882". El Trabajo, Tarija, 28.08.1882: 2.

Stazi, L. (1882). Carta al P. Giannecchini, 7.09.1882. AFT 2-574.

Thouar, A. (1884). "À la recherche des restes de la mission Crevaux". Le Tour du Monde, XLVIII: 209-272.

Thouar, A. (1899). Circonstances qui ont précédé et suivi le massacre de la mission Crevaux. ANF/17/3009B, dossier Thouar.
Tratado (1884). Tratado de paz, 14.09.1884. AFT 1-910.

Van Nivel, E. (1844). "Carta al ministro de guerra y marina. Villa Rodrigo, 3.11.1844". Gaceta del Gobierno, 14.12.1844: 2-3

Van Nivel, E. (1845). "Diario de la flotilla Bolívar en su exploración del río Pilcomayo". Gaceta del Gobierno, 6.03.1845: 3-4; 8.03.1845: 3-4; 11.03.1845: 3-4; 13.03.1845: 2-3; 15.03.1845: 3-4.

Weddell, H. A. (2018). Viaje en el sur de Bolivia (18451846). Santa Cruz: El País/CIHA. (Original en francés, 1851). 